\title{
Comparison of antibiotic discs from different sources
}

\author{
D. F. J. BROWN ${ }^{1}$ AND D. KOTHARI
}

From the Division of Hospital Infection, Clinical Research Centre, Harrow, Middlesex HA1 $3 U$ U and Cross-Infection Reference Laboratory, Central Public Health Laboratory, London NW9 5 HT

SYNOPSIS Antibiotic discs from Oxoid, Mast, AB Biodisk, Difco, and Baltimore Biological Laboratories were compared, where discs of similar antibiotic content were available, in diffusion-sensitivity tests against organisms of known sensitivity. Discs from Oxoid and Mast gave zones 1-5 mm larger than discs from other manufacturers with penicillin 2 units, ampicillin $10 \mu \mathrm{g}$, cephalothin $30 \mu \mathrm{g}$, methicillin $10 \mu \mathrm{g}$, carbenicillin $100 \mu \mathrm{g}$, erythromycin $15 \mu \mathrm{g}$, chloramphenicol $50 \mu \mathrm{g}$, and trimethoprim $1.25 \mu \mathrm{g}$, while discs containing aminoglycoside antibiotics, lincomycin, fusidic acid, tetracycline, nalidixic acid, penicillin 10 units, and polymyxin B gave similar zone sizes whatever the source. Where tested, different batches of single discs from the same source did not vary significantly in antibiotic content as indicated by variation in zone size; but with some antibiotics Multodisks gave larger zones than single discs from the same source. The implications of these differences are discussed.

Variation in antibiotic-sensitivity tests may be caused by several factors, all of which have been shown to contribute towards inaccuracy and lack of reproducibility in routine testing (Bauer, 1964; Garrod and Waterworth, 1971; Ericsson and Sherris, 1971; Garrod, Lambert, and O'Grady, 1973). It is reasonable to expect that discs contain the stated antimicrobial agent in the amount specified, yet antibiotic discs are prominent in the list of variable factors mentioned by the authors quoted above.

Incorrect antibiotic content of discs may result from errors in handling in the laboratory or faulty production by the makers. Humidity and temperature affect the stability of antibiotics in discs (Griffith and Mullins, 1968; Ericsson and Sherris, 1971; Drew et al, 1972), so discs should be stored in sealed containers, preferably containing a dessicant, at $4^{\circ} \mathrm{C}$ or below, and allowed to warm up to room temperature before containers are opened.

Faults in the production of discs may be (1) incorrect storage by the makers, (2) incorporation of the wrong antimicrobial agent, or (3) incorporation of the incorrect amount of antibiotic. Manufacturers should be sufficiently aware to avoid the first failing, but there is evidence that discs may occasionally contain antibacterial substances other than or in addition to those quoted on the label

'Present address: Microbiology Quality Control Laboratory, Neasden Hospital, Brentfield Road, London NW10 8EY

Received for publication 14 April 1975.
(Brown and Selkon, 1974). Such discs would seldom be detected by the inclusion of the normal controls in disc-sensitivity testing, and the frequency with which they occur is very difficult to estimate. They are, however, potentially more dangerous than 'non-reacting' discs, because with them a resistant organism may be reported as sensitive.

Accuracy of the stated disc content has become more important as methods have become more standardized. If zone sizes are interpreted from a table, as in the FDA method (Federal Register, 1972) used in the USA and the ICS method (Ericsson and Sherris, 1971) used in Sweden, variations in the disc content that result in differences in zone sizes of only a few millimetres may considerably alter the interpretation of the test. The only country known to us in which there are statutory limits for acceptable variation in antibiotic content of discs is the USA where discs must contain $67-150 \%$ of their stated content. This statutory control has undoubtedly greatly improved the standard of sensitivity discs in the USA. In 1958 the FDA found that $44-100 \%$ of discs produced by six manufacturers failed to meet FDA standards (Wright, 1974), whereas by 1971 only around $2 \%$ of the lots tested were rejected.

All manufacturers would no doubt claim to produce discs well within the FDA tolerances. Commercially manufactured discs are often designed for use in the testing method accepted in the country of manufacture, but they may be sold in other 
countries in which different methods are used. It is therefore important to know whether this is likely to cause differences in the interpretation of sensitivity tests. The aim of this study was to compare discs from different manufacturers who produce discs with a similar stated content of antibiotic.

\section{Materials and Methods}

Antibiotic discs were obtained by ordering through normal channels from Oxoid, Mast, Difco, Baltimore Biological Laboratories, and AB Biodisk, Sweden. When possible discs from more than one batch were obtained from each manufacturer. Multodisks (Oxoid) were compared with single discs by cutting the tips of the Multodisks off the arms. All discs were stored in their unopened containers at $-20^{\circ} \mathrm{C}$ until used for these experiments.

Comparison of discs was made on medium in $235 \mathrm{~mm}$ square Bio-assay dishes (A/S Nunc, Denmark; UK Agent: Jobling, Stone, Staffordshire). Sensitest agar (Oxoid CM409) was prepared and sterilized as directed by the makers; $150 \mathrm{ml}$ of medium was poured into each dish on a horizontal surface to give a depth of $3 \mathrm{~mm}$. The plate was seeded with an appropriate organism by the agaroverlay method. An overnight nutrient-broth culture of the organism was diluted in melted Sensitest agar that had been cooled to $48^{\circ} \mathrm{C}$. A dilution of $1: 500$ for staphylococci and 1:5000 for Gram-negative organisms gave semiconfluent growth of colonies in the overlay after overnight incubation. The suspension of organisms in agar was poured over the base layer (prewarmed to $37^{\circ} \mathrm{C}$ ) to a depth of in $1 \mathrm{~mm}(50 \mathrm{ml}$ of medium). After the agar had set the seeded plates were dried for 30 minutes at $37^{\circ} \mathrm{C}$ before discs were applied. On each plate, 36 discs could be accommodated without confluence of zones, and in most experiments six discs from each of six sources-each stated to contain the same antibiotic at the same strength-were applied in a Latin-square arrangement. Plates were incubated immediately at $37^{\circ} \mathrm{C}$ for 18 hours and zones were measured with sliding calipers and dark-ground illumination.

The bacterial strains used were identified as follows, and will be referred to in the tables by the numbers 1-20:

(1) Staphylococcus aureus (NCTC No. 6571); (2-9) Staph. aureus; (10) Escherichia coli (NCTC No $\overrightarrow{0}$

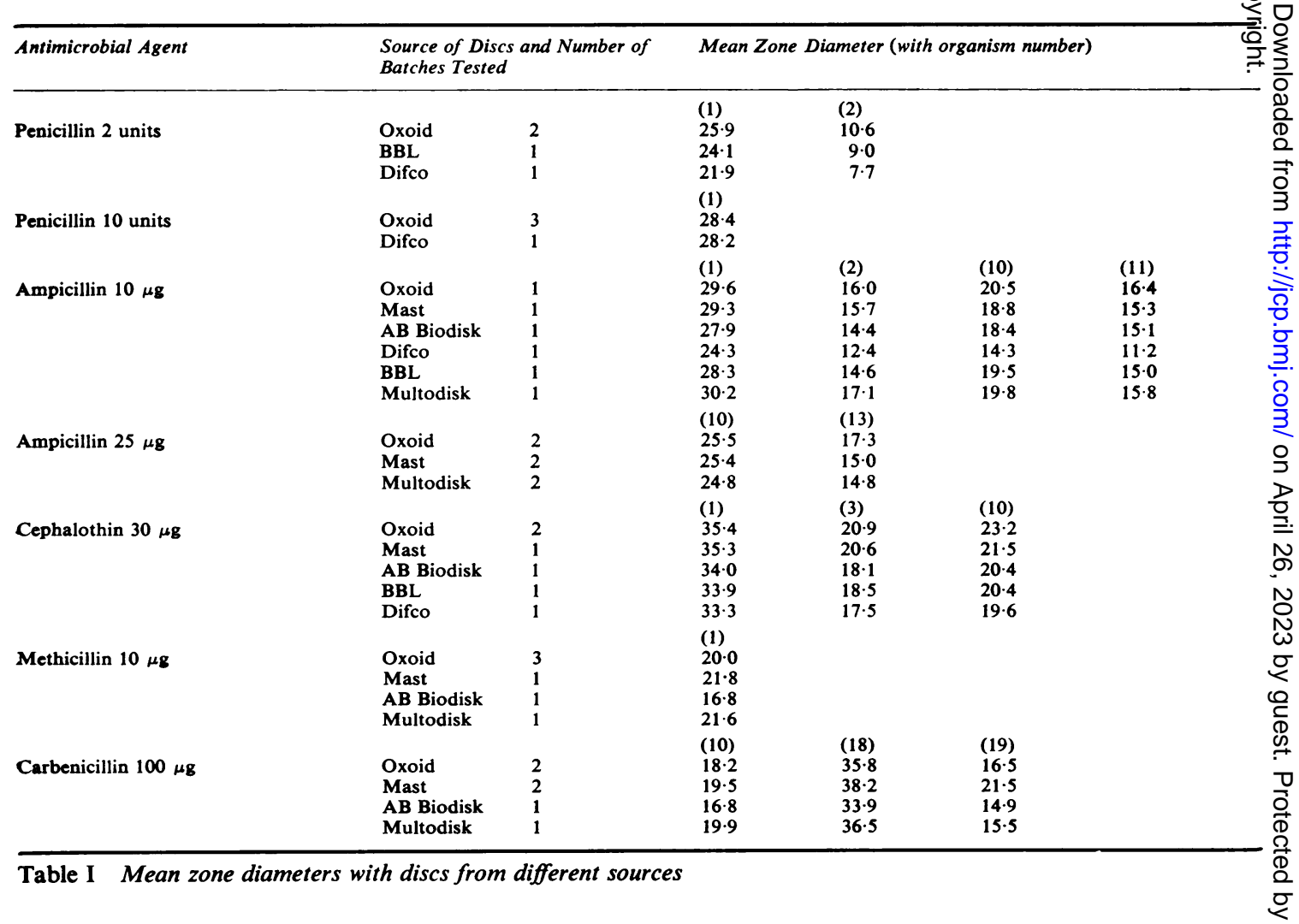




\begin{tabular}{|c|c|c|c|c|c|c|}
\hline Antimicrobial Agent & \multicolumn{2}{|c|}{$\begin{array}{l}\text { Source of Discs and Number } \\
\text { of Batches Tested }\end{array}$} & \multicolumn{4}{|c|}{ Mean Zone Diameter (with organism number) } \\
\hline Gentamicin $10 \mu \mathrm{g}$ & $\begin{array}{l}\text { Oxoid } \\
\text { Mast } \\
\text { BBL } \\
\text { Difco }\end{array}$ & $\begin{array}{l}3 \\
1 \\
1 \\
1\end{array}$ & $\begin{array}{l}(1) \\
21 \cdot 6 \\
23 \cdot 6 \\
20.9 \\
20.5\end{array}$ & $\begin{array}{l}(4) \\
18 \cdot 0 \\
20 \cdot 1 \\
18 \cdot 1 \\
17 \cdot 9\end{array}$ & $\begin{array}{l}(10) \\
22 \cdot 5 \\
23 \cdot 8 \\
21 \cdot 9 \\
21 \cdot 3\end{array}$ & $\begin{array}{l}(14) \\
18 \cdot 2 \\
18 \cdot 9 \\
18 \cdot 0 \\
17 \cdot 2\end{array}$ \\
\hline Kanamycin $30 \mu \mathrm{g}$ & $\begin{array}{l}\text { Oxoid } \\
\text { AB Biodisk } \\
\text { BBL } \\
\text { Difco } \\
\text { Multodisk }\end{array}$ & $\begin{array}{l}1 \\
1 \\
1 \\
2 \\
1\end{array}$ & $\begin{array}{l}\text { (1) } \\
18 \cdot 8 \\
19 \cdot 4 \\
19 \cdot 6 \\
18 \cdot 9 \\
21 \cdot 8\end{array}$ & $\begin{array}{l}(10) \\
19 \cdot 4 \\
20 \cdot 1 \\
20 \cdot 4 \\
20 \cdot 0 \\
22 \cdot 4\end{array}$ & $\begin{array}{l}(20) \\
13 \cdot 2 \\
13 \cdot 9 \\
15 \cdot 4 \\
13 \cdot 6 \\
17 \cdot 7\end{array}$ & \\
\hline Streptomycin $10 \mu \mathrm{g}$ & $\begin{array}{l}\text { Oxoid } \\
\text { Mast } \\
\text { BBL } \\
\text { Difco }\end{array}$ & $\begin{array}{l}3 \\
1 \\
1 \\
1\end{array}$ & $\begin{array}{l}(1) \\
16 \cdot 7 \\
14 \cdot 7 \\
16 \cdot 3 \\
15 \cdot 3\end{array}$ & $\begin{array}{l}(4) \\
15 \cdot 5 \\
13 \cdot 9 \\
15 \cdot 3 \\
14 \cdot 1\end{array}$ & $\begin{array}{l}(10) \\
18 \cdot 8 \\
14 \cdot 5 \\
16 \cdot 7 \\
15 \cdot 7\end{array}$ & $\begin{array}{l}(11) \\
17.7 \\
15.4 \\
15.9 \\
15.4\end{array}$ \\
\hline Neomycin $30 \mu \mathrm{g}$ & $\begin{array}{l}\text { Oxoid } \\
\text { Mast } \\
\text { AB Biodisk } \\
\text { BBL } \\
\text { Difco } \\
\text { Multodisk }\end{array}$ & $\begin{array}{l}1 \\
1 \\
1 \\
1 \\
1 \\
1\end{array}$ & $\begin{array}{l}(1) \\
20 \cdot 1 \\
20 \cdot 6 \\
20 \cdot 2 \\
20 \cdot 5 \\
20 \cdot 2 \\
21 \cdot 6\end{array}$ & $\begin{array}{l}\text { (5) } \\
11 \cdot 1 \\
11 \cdot 2 \\
11 \cdot 4 \\
12 \cdot 0 \\
11 \cdot 5 \\
10 \cdot 3\end{array}$ & $\begin{array}{l}(10) \\
20 \cdot 7 \\
21 \cdot 0 \\
20 \cdot 8 \\
21 \cdot 2 \\
20.6 \\
21 \cdot 6\end{array}$ & \\
\hline Erythromycin $15 \mu \mathrm{g}$ & $\begin{array}{l}\text { Oxoid } \\
\text { AB Biodisk } \\
\text { BBL } \\
\text { Difco }\end{array}$ & $\begin{array}{l}2 \\
1 \\
1 \\
1\end{array}$ & $\begin{array}{l}(1) \\
28 \cdot 7 \\
26 \cdot 8 \\
27 \cdot 5 \\
27 \cdot 4\end{array}$ & $\begin{array}{l}(2) \\
25 \cdot 8 \\
24 \cdot 6 \\
25 \cdot 5 \\
25 \cdot 7\end{array}$ & $\begin{array}{l}(6) \\
22 \cdot 4 \\
20 \cdot 9 \\
21 \cdot 2 \\
21 \cdot 0\end{array}$ & \\
\hline Lincomycin $2 \mu \mathrm{g}$ & $\begin{array}{l}\text { Oxoid } \\
\text { Mast } \\
\text { Difco } \\
\text { BBL } \\
\text { Multodisk }\end{array}$ & $\begin{array}{l}1 \\
1 \\
1 \\
1 \\
1\end{array}$ & $\begin{array}{l}\text { (1) } \\
17 \cdot 3 \\
18 \cdot 1 \\
16 \cdot 8 \\
17 \cdot 2 \\
19 \cdot 8\end{array}$ & $\begin{array}{l}\text { (4) } \\
18 \cdot 4 \\
18 \cdot 6 \\
18 \cdot 1 \\
19 \cdot 0 \\
19 \cdot 6\end{array}$ & $\begin{array}{l}\text { (7) } \\
17 \cdot 1 \\
17 \cdot 7 \\
16 \cdot 9 \\
17 \cdot 4 \\
18 \cdot 4\end{array}$ & \\
\hline Fusidic acid $10 \mu \mathrm{g}$ & $\begin{array}{l}\text { Oxoid } \\
\text { Mast } \\
\text { Multodisk }\end{array}$ & $\begin{array}{l}3 \\
1 \\
2\end{array}$ & $\begin{array}{l}(1) \\
26 \cdot 7 \\
27 \cdot 2 \\
29 \cdot 8\end{array}$ & $\begin{array}{l}(7) \\
26 \cdot 1 \\
25 \cdot 8 \\
29 \cdot 2\end{array}$ & $\begin{array}{l}(8) \\
22 \cdot 6 \\
22 \cdot 5 \\
24 \cdot 7\end{array}$ & \\
\hline
\end{tabular}

Table II Mean zone diameters with discs from different sources

10418); (11-12) E. coli; (13-16) Klebsiella aerogenes; (17) Serrati sp; (18-19) Pseudomonas aeruginosa; (20) Acinetobacter sp.

They were chosen to represent various degrees of sensitivity to the antibiotics incorporated in the discs. In tests on each type of disc two to four of these organisms were used, including, whenever possible, strains with 'intermediate' sensitivity to the appropriate antibiotic.

\section{Results}

Tables I to III show mean zone diameters obtained when comparable antibiotic discs from different sources were tested against the various organisms. Discs from Oxoid and Mast-with the exception of nitrofurantoin discs-generally gave zones of inhibition of similar size. Nitrofurantoin $200 \mu \mathrm{g}$ discs from Mast gave zones 3-6 mm larger than similar discs from Oxoid. With penicillin 2 units, ampicillin $10 \mu \mathrm{g}$, cephalothin $30 \mu \mathrm{g}$, methicillin $10 \mu \mathrm{g}$, carbenicillin $100 \mu \mathrm{g}$, erythromycin $15 \mu \mathrm{g}$, chloramphenicol
$50 \mu \mathrm{g}$, and trimethoprim $1.25 \mu \mathrm{g}$ ' discs from Oxoid and Mast generally gave zones 1-5 mm larger than discs from the other sources. There were no consistent and significant differences in mean zone size between single discs from different sources with aminoglycoside antibiotics, lincomycin, fusidic acid, tetracycline, nalidixic acid, penicillin 10 units, and polymyxin $\mathbf{B}$.

Different batches of discs from the same source gave mean zone diameters differing by less than $1 \mathrm{~mm}$ in all but five instances; in these the means differed by less than $2 \mathrm{~mm}$. Multodisks gave consistently larger zones than single discs from the same source with polymyxin B $\mathbf{3 0 0}$ units, nitrofurantoin $200 \mu \mathrm{g}$, and methicillin $10 \mu \mathrm{g}$.

Variability of zone diameter in replicate tests with discs from the same source was not investigated in detail. This probably included a component, attributable to the position of the individual discs on the plate, that would mask small differences in zone size caused by variation between discs. In fact, there were no obvious differences in the variability of 


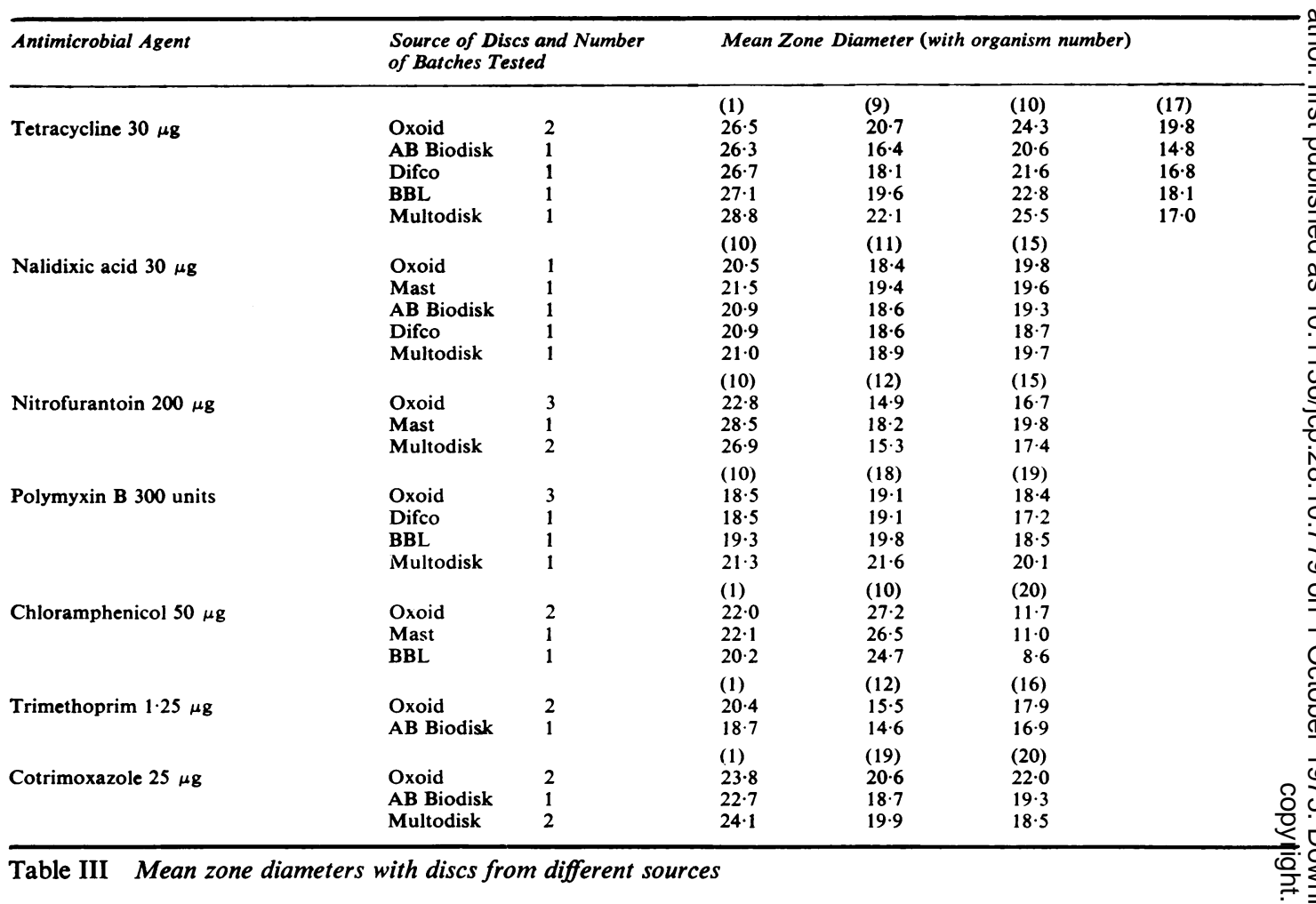

results obtained with comparable discs from different manufacturers. The range of zone diameters was generally less than $2 \mathrm{~mm}$, and exceeded $3 \mathrm{~mm}$ in less than $5 \%$ of tests.

\section{Discussion}

Comparison of discs from different sources was somewhat limited by the fact that all manufacturers do not produce discs with the same content for all antibiotics. Sensitivity-testing methods used in different countries specify some different disc contents, and the manufacturers obviously produce only discs for which there is a demand. Of the antibiotics tested, about half showed no significant difference in zone size between manufacturers. With antibiotics for which there were differences between manufacturers, the discs from British sources generally gave wider zones than did American and Swedish discs. Because different batches of discs from the same source gave consistent results, the differences may be due to differences in the testing methods adopted by manufacturers in various countries; but perhaps different levels of impregnation are chosen for some antibiotics by different manufacturers. It may be that some discs are impregnated with more than $100 \%$ of the stated $\frac{0}{\otimes}$ content to compensate for loss of activity in the $\stackrel{\varrho}{\Rightarrow}$ handling of discs, particularly those containing penicillins.

The use of different types of paper for discs in different countries is most unlikely to be the cause of the differences found as Ericsson and Sherris? (1971) reported no clear differences between 11 kinds $\overline{0}$ of paper used by makers of discs in different count- 3 . ries, and Ostrander and Griffith (1958-59) found no $ᄋ$ differences between nine undyed papers tested. The above authors reported the inhibitory effects of dyes 의 in paper discs but the majority of the discs tested $\supset$ were not dyed and manufacturers should now be을. well aware of these pitfalls.

Differences in disc content are particularly sig- $N$ nificant for methods that are closely defined and in $N$ which zone sizes are interpreted from a table (the American FDA and Swedish ICS methods). If discs from British manufacturers are used in these methods, some organisms will appear to be more sensitive to some antibiotics than if American or $\stackrel{\mathcal{P}}{+}$ Swedish discs are used. In most instances the effect 0 on interpretation of the test result will be minor, but $\bar{P}$

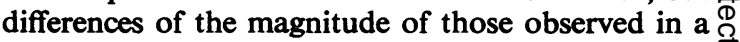
few of the tests might result in an organism of inter- $\frac{\mathbb{Q}}{\mathbb{8}}$ 
mediate sensitivity being reported as sensitive or resistant according to the source of the disc used. For example, with organism No. 1 when tested against $10 \mu \mathrm{g}$ methicillin discs, the AB Biodisk discs gave zones up to $5 \mathrm{~mm}$ smaller than the Oxoid and Mast discs. The ICS method has no 'intermediate' category for methicillin; a strain that gave a zone size close to the 'breakpoint' therefore might be reported as resistant if tested with discs from $\mathrm{AB}$ Biodisk and sensitive if tested with an Oxoid or Mast disc. Several 'intermediate' categories in the FDA method cover only $2-4 \mathrm{~mm}$, and a few of the differences we observed were larger than this.

Methods in which results are interpreted by comparison of the zone of inhibition of the test organism with that given by a control organism examined under the same conditions at the same time will not be so much affected by consistent differences in antibiotic content of the magnitude that we observed.

The number of different batches of the same antibiotic disc obtained from each manufacturer was influenced by the availability and turnover of discs from each source in Great Britain; hence comparison of different batches was limited mainly to dises from Oxoid, and variations between batches exceeding $1 \mathrm{~mm}$ occurred rarely. However, with some antimicrobial agents Multodisks gave consistently larger zones than single discs from the same source. Why Multodisks should apparently be impregnated with more antibiotic than single discs is not clear, unless it is assumed that they are not stored as carefully as single discs in routine laboratories, and overimpregnation is to compensate for this.

It was surprising that nitrofurantoin $200 \mu \mathrm{g}$ discs from Mast gave zones up to $6 \mathrm{~mm}$ larger than zones with similar discs from Oxoid. This may have been due to differences in drug content of the discs or to differences in the $\mathrm{pH}$ of the discs (Hoo and Drew, 1974), a higher $\mathrm{pH}$ resulting in more rapid diffusion of the drug content into the culture medium, and consequently a larger zone of inhibition.

The discs from different sources that gave different results in our hands may possibly have conformed to the FDA standard of antibiotic content, but this permits a greater than twofold difference. With the more diffusible antibiotics a doubling of antibiotic content may increase the diameter of the zone of inhibition of a sensitive organism by as much as $7 \mathrm{~mm}$. Caution should therefore be exercised in interpreting the results of sensitivity tests in terms of an 'absolute' scale of zone diameter, unless it is known that the scale had been established with discs giving similar zone sizes to discs from the source used. If such methods of interpreting disc-sensitivity tests are to be used widely, it may well be that the acceptable limits for the antibiotic content of discs must be narrower for some antibiotics than those at present required by the FDA.

We are grateful to Dr R. Blowers, Clinical Research Centre, Harrow, and to Dr M. T. Parker, Central Public Health Laboratory, Colindale, for helpful criticism.

\section{References}

Bauer, W. W. (1964). The significance of bacterial inhibition zone diameters. A study of the factors influencing antibiotic disc sensitivity tests. Proc. III int. Congr. Chemother., Stuttgart, pp. 466-479.

Brown, D. F. J. and Selkon, J. B. (1974). Antibiotic discs active against resistant organisms. Brit. med. J., 1, 573. [Letter]

Drew, W. L., Barry, A. L., O'Toole, R., and Sherris, J. C. (1972). Reliability of the Kirby-Bauer disc diffusion method for detecting methicillin-resistant strains of Staphylococcus aureus. Appl. Microbiol., 24, 240-247.

Ericsson, H. M. and Sherris, J. C. (1971). Antibiotic sensitivity testing. Report of an International Collaborative Study. Acta. path. Microbiol. Scand., Sec. B, Suppl. No. 217.

Federal Register (1972). 37, 20525-20529.

Garrod, L. P., Lambert, H. P., and O'Grady, F. (1973). Antibiotic and Chemotherapy, 4th ed., pp. 491-496. Churchill Livingstone, Edinburgh and London.

Garrod, L. P. and Waterworth, P. M. (1971). Tests of bacterial sensitivity to drugs. Disease-a-month, July, 1-48.

Griffith, L. J. and Mullins, C. G. (1968). Drug resistance as influenced by inactivated sensitivity discs. Appl. Microbiol., 16, 656-658.

Hoo, R. and Drew, W. L. (1974). Potential unreliability of nitrofurantoin disks in susceptibility testing. Antimicrob. Agents Chemother., 5, 607-610.

Ostrander, W. E. and Griffith, L. J. (1958-59). An evaluation of different types of paper concerning their suitability for sensitivity discs. Antibiotics Annual, pp. 813-817.

Wright, W. W. (1974). FDA Actions on antibiotic susceptibility discs. In Current Techniques for Antibiotic Susceptibility Testing, edited by A. Balows, pp. 24-26. Thomas, Springfield, USA. 